\title{
Minimum inhibitory concentration (MIC) determination of herbal extracts against Escherichia coli, Salmonella Typhimurium, and Staphylococcus aureus
}

\author{
Vu T. Pham, Tue T. Nguyen, Nga T. T. Tran, Vu Tran, Hien B. T. Le, \\ Tien T. Tran*, \& An T. T. Vo
}

Faculty of Animal Science and Veterinary Medicine, Nong Lam University, Ho Chi Minh City, Vietnam

\begin{tabular}{|c|c|}
\hline ARTICLE INFO & ABSTRACT \\
\hline $\begin{array}{l}\text { Received: December } 29,2017 \\
\text { Revised: January } 15,2018 \\
\text { Accepted: January 24, } 2018 \\
\text { Keywords } \\
\text { Azadirachta indica } \\
\text { Camellia sinensis } \\
\text { Eclipta prostrata L. } \\
\text { Pseuderanthemum palatiferum } \\
\text { Psidium guajava } \\
\text { * Corresponding author } \\
\text { Tran Thanh Tien } \\
\text { Email: tien tranthanh@hcmuafedu v }\end{array}$ & 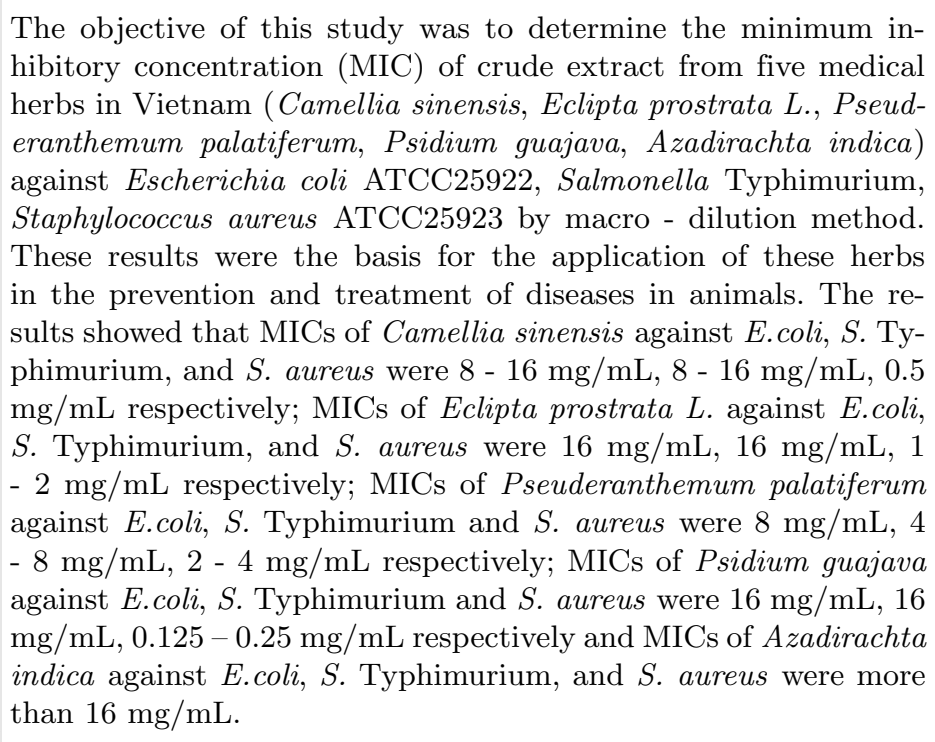 \\
\hline
\end{tabular}

Cited as: Pham, V. T., Nguyen, T. T., Tran, N. T. T., Tran V., Le, H. B. T., Tran, T. T., \& Vo, A. T. T. (2018). Minimum inhibitory concentration (MIC) determination of herbal extracts against Escherichia coli, Salmonella Typhimurium, and Staphylococcus aureus. The Journal of Agriculture and Development 17(4), 62-67. 


\section{Khảo sát nồng độ ức chế tối thiểu $(\mathrm{MIC})$ của cao thô chiết xuất từ một số thảo dược đối với Escherichia coli, Salmonella Typhimurium và Staphylococcus aureus}

Phạm Trọng Vũ, Nguyễn Trí Tuệ, Trần Thị Thúy Nga, Trần Vũ, Lê Bá Thị Hiền, Trần Thanh Tiến* \& Võ Thị Trà An

Khoa Chăn Nuôi Thú Y, Trường Đại Học Nông Lâm TP. Hồ Chí Minh, TP. Hồ Chí Minh

THÔNG TIN BÀI BÁO
Bài báo khoa học
Ngày nhận: $29 / 12 / 2017$
Ngày chỉnh sưa: $15 / 01 / 2018$
Ngày chấp nhận: $24 / 01 / 2018$
Từ khóa
Chè xanh
Cỏ mực
Hoàn ngọc
Ối
Sầu đâu (neem)
*Tác giả liên hệ

\section{1. Đặt Vấn Đề}

Trong một thời gian dài, việc sử dụng kháng sinh trong chăn nuôi được xem mang lại nhiều hiệu quả trong phòng và điều trị bệnh. Ngoài ra, việc sử dụng các kháng sinh phổ rộng trong thức ăn với liều lượng thấp còn cho rằng có hiệu quả kích thích tăng trọng (Gustafson \& Bowen, 1997). Điều này dẫn đến tình trạng tồn dư kháng sinh trong các sản phẩm chăn nuôi (thịt, sữa, trứng....) và tạo ra những chủng vi khuẩn đề kháng kháng sinh (Madhab, 2014).

Chính vì vậy, nhiều giải pháp được đưa ra nhằm thay thế vai trò của kháng sinh trong phòng trị bệnh như vaccin, probiotic, chiết xuất thực vật... Các giải pháp này nhằm mục tiêu làm giảm tác dụng phụ do kháng sinh gây ra hoặc làm giảm hậu quả của tình trạng lạm dụng kháng sinh như tồn dư kháng sinh, sự đề kháng kháng sinh của vi khuẩn...nhưng vẫn đảm bảo sức khỏe và tăng trưởng cho vật nuôi. Trong đó, việc ứng dụng các hoạt chất có nguồn gốc thiên nhiên đang được xem là các giải pháp tốt nhằm nâng cao năng suất, chất lượng và sức khỏe vật nuôi (Do, 2006; Nguyen, 2012).

Việt Nam có khí hậu nhiệt đới nên có nguồn dược liệu phong phú và đa dạng về chủng loại. Do đó, tiềm năng ứng dụng các loại thảo dược trong chăn nuôi thú y là rất lớn. Mục tiêu của nghiên cứu là xác định nồng độ ức chế tối thiểu (MIC) của cao thô chiết từ 5 loại thảo dược phổ biến ở Việt Nam (sầu đâu, hoàn ngọc, chè, ổi, cỏ mực) trên một số vi khuẩn gây bệnh nhằm làm cơ sở cho việc ứng dụng các loại thảo dược này trong phòng và trị bệnh trên vật nuôi.

\section{Vật Liệu và Phương Pháp Nghiên Cứu}

\subsection{Cao chiết thô các loại thảo dược}

Các thảo dược sau khi thu hái từ Bà Rịa - Vũng Tàu (hoàn ngọc, ổi, cỏ mực), Bình Thuận (sầu 
đâu), Lâm Đồng (chè) sẽ được làm sạch, để trong bóng râm, thoáng gió cho ráo nước sau đó xay nhuyễn. Cân 250 gam thảo dược cho vào $750 \mathrm{ml}$ nước cất, khuấy đều và đun cách thủy trong 3 giờ sau đó thu dịch lọc. Dịch lọc được làm cô đặc lại bằng hệ thống cô quay chân không (thu nhận cao thô). Cao thô được bảo quản trong lọ kín ở nhiệt độ $2-4^{0} \mathrm{C}$.

\subsection{Gốc vi khuẩn dùng trong nghiên cứu}

Các chủng vi khuẩn được sử dụng trong nghiên cứu bao gồm: Escherichia coli ATCC 25922, Staphylococcus aureus ATCC 25923 (Vo \& ctv., 2010) và Salmonella Typhimurium phân lập từ đường ruột heo bệnh (Vo \& ctv., 2006). Các gốc vi khuẩn này từ ống giữ gốc trong glycerol ở $-20^{\circ} \mathrm{C}$ được tăng sinh trong môi trường Brain Heart Infusion (BHI), (Oxoid, CM1135, Anh) và ủ ở $37^{0} \mathrm{C}$ trong 24 giờ trước khi cấy trên các môi trường chuyên biệt.

- E. coli ATCC 25922: Vi khuẩn sau khi tăng sinh trong BHI được cấy trên thạch Eosin Methylene Blue (EMB), (CM0069, Oxoid, Anh) và ủ ở $37^{0} \mathrm{C}$ trong 24 giờ. Sau đó, những khuẩn lạc rời có màu tím ánh kim sẽ được chọn để cấy ria lên thạch Nutrient (NA), (CM0003, Oxoid, Anh) dể thu lấy khuẩn lạc rời.

- Salmonella Typhimurium: Sau khi tăng sinh trong BHI, canh khuẩn tiếp tục được cấy ria lên thạch Xylose Lysine Deoxycholate (XLD), (CM0469, Oxoid, Anh) và ủ ở $37^{0} \mathrm{C}$ trong 24 giờ. Sau đó, những khuẩn lạc rời có màu đỏ, tâm đen sẽ được chọn để cấy ria lên thạch NA để thu lấy khuẩn lạc rời.

- Staphylococcus aureus ATCC 25923:

Vi khuẩn sau khi tăng sinh được cấy trên thạch máu (BA), (MI092AP, Nam Khoa, Việt Nam) và ủ ở $37^{0} \mathrm{C}$ trong 24 giờ. Chọn những khuẩn lạc rời, nhẵn, đục, màu vàng nhạt và có vòng dung huyết đôi để cấy ria lên thạch NA để thu lấy khuẩn lạc rời.

Khuẩn lạc rời của mỗi loại vi khuẩn thu trên bề mặt thạch NA được đánh tan vào nước muối sinh lý vô trùng để đạt nồng độ vi khuẩn khoảng 108 $\mathrm{CFU} / \mathrm{mL}$ bằng cách so màu với độ đục chuẩn Mac Farland 0,5. Pha loãng dung dịch canh khuẩn này 100 lần để đạt nồng độ vi khuẩn khoảng $10^{6} \mathrm{CFU} / \mathrm{mL}$ bằng môi trường $\mathrm{MHB}$ (Wiegand \& ctv., 2008). Nồng độ vi khuẩn này sẽ được kiểm chứng sau đó bằng cách cấy trang lên môi trường thạch dinh dưỡng để đếm số lượng khuẩn lạc (Wiegand \& ctv., 2008).

\subsection{Kháng sinh chuẩn đối chứng}

Các kháng sinh đối chứng đối chứng dùng trong thí nghiệm bao gồm amoxicillin (tinh khiết 99\%) (UV, Việt Nam), colistin sulfate (tinh khiết

99\%) (UV, Việt Nam), enrofloxacin (tinh khiết 99\%) (UV, Việt Nam). Amoxicillin được hòa tan bằng dung dịch đệm phosphate $\mathrm{pH} 6.0$; $0,1 \mathrm{~mol} / \mathrm{l}$; colistin sulfate được hòa tan bằng nước và enrofloxacin cũng được hòa tan trong nước nhưng phải được kiềm hóa bằng $\mathrm{NaOH} 0,1$ mol/l (Victor, 2005). Các kháng sinh sau khi hòa tan trong dung môi tạo thành dung dịch gốc có nồng độ là $1 \mathrm{mg} / \mathrm{mL}$. Mỗi loại dung dịch kháng sinh gốc này sẽ tiếp tục được pha loãng 100 lần trước khi pha loãng thành dãy các nồng độ giảm dần theo cấp số 2 từ $10 \mu \mathrm{g} / \mathrm{mL}$ đến $0,01 \mu \mathrm{g} / \mathrm{mL}$ bằng Muller Hinton Broth (MHB), (CM0405, Oxoid, Anh) (Wiegand \& ctv., 2008).

\subsection{Phương pháp xác định MIC}

Cân chính xác 32mg mỗi loại cao thảo dược hòa tan vào $1 \mathrm{~mL}$ nước cất, sau đó pha loãng các cao này bằng môi trường MHB (Muller Hinton Broth - Oxoid) tạo thành 1 dãy 11 ông chứa dung dịch cao thô (mỗi ống chứa $1 \mathrm{~mL}$ ) có nồng độ giảm dần theo cấp số 2 (Wiegand \& ctv., 2008) với các nồng độ lần lượt là: $32 \mathrm{mg} / \mathrm{mL} ; 16 \mathrm{mg} / \mathrm{mL} ; 8 \mathrm{mg} / \mathrm{mL}$; $4 \mathrm{mg} / \mathrm{mL} ; 2 \mathrm{mg} / \mathrm{mL} ; 1 \mathrm{mg} / \mathrm{mL} ; 0,5 \mathrm{mg} / \mathrm{mL} ; 0,25$ $\mathrm{mg} / \mathrm{mL} ; 0,125 \mathrm{mg} / \mathrm{mL} ; 0,0625 \mathrm{mg} / \mathrm{mL} ; 0,03125$ $\mathrm{mg} / \mathrm{mL}$. Các ống chứa cao pha loãng này sau đó được hấp tiệt trùng ở $121^{\circ} \mathrm{C}$ trong 15 phút.

Giá trị MIC của 1 loại thảo dược đối với 1 loại vi khuẩn được xác định bằng phương pháp pha loãng tới hạn (Wiegand \& ctv. 2008). Cho $1 \mathrm{~mL}$ vi khuẩn (khoảng $10^{6} \mathrm{CFU} / \mathrm{mL}$ ) lần lượt vào các dãy ống có chứa $1 \mathrm{~mL}$ loại thảo dược với nồng độ giảm dần. Đồng thời thêm $1 \mathrm{~mL}$ môi trường MHB vô trùng thay cho vi khuẩn ở dãy ống dối chứng (Wiegand \& ctv., 2008). Như vậy, sau khi thực hiện pha loãng, nồng độ thảo dược trong các ống giảm đi một nửa so với lúc đầu và nồng độ vi khuẩn cuối cùng trong ống vào khoảng $5 \times 10^{5}$ $\mathrm{CFU} / \mathrm{mL}$. MIC của kháng sinh đối chứng đối chứng (amoxicillin, colistin, enrofloxacin) cũng được thực hiện tương tự như trên. Tất cả các ông sau đó được ủ ở $37^{\circ} \mathrm{C}$ trong $16-24$ giờ. Mỗi 
nghiệm thức được lặp lại 3 lần.

Giá trị MIC được định nghĩa là nồng độ thấp nhất của chất có hoạt tính kháng khuẩn (trong $1 \mathrm{~mL}$ ) mà có khả năng ức chế sự phát triển của vi sinh vật trong điều kiện xác định (Wiegand \& ctv., 2008).

\section{Kết Quả và Thảo Luận}

\subsection{Nồng độ ức chế tối thiểu của các loại thảo dược}

Thử nghiệm xác định nồng độ ức chế tối thiểu (MIC) của các 5 loại thảo dược được xác định bằng phương pháp pha loãng tới hạn. Kết quả nồng độ ức chế tối thiểu của 5 loại thảo dược và 3 loại kháng sinh đối với 3 chủng vi khuẩn được trình bày trong Bảng 1 và Bảng 2 .

- Nồng độ ức chế tối thiểu của cao thô chè xanh:

Kết quả của nghiên cứu cho thấy nồng độ ức chế tối thiểu của cao chiết thô của chè xanh đối với hai chủng vi khuẩn $E$. coli và Salmonella dao động từ $8-16 \mathrm{mg} / \mathrm{mL}$. Khả năng kháng khuẩn này tương đương với amoxicillin $(2,5 \mu \mathrm{g} / \mathrm{mL})$, colistin $(0,16 \mu \mathrm{g} / \mathrm{mL})$ và enrofloxacin $(0,01 \mu \mathrm{g} / \mathrm{mL})$. Nghiên cứu khác của Amber \& ctv. (2015) xác định nồng độ ức chế tối thiểu của cao chiết bằng nước từ lá chè xanh đối với $E$. coli ATCC 25922 và $S$. Typhi ATCC 13311 là $3,12 \mathrm{mg} / \mathrm{mL}$; trong khi cao chiết bằng methanol của loại thảo dược này có nồng độ ức chế tối thiểu đối với $E$. coli ATCC 25922 và $S$. Typhi ATCC 13311 lần lượt là $5 \mathrm{mg} / \mathrm{mL}$ và $2,5 \mathrm{mg} / \mathrm{mL}$. MIC của cao chiết bằng methanol từ lá chè xanh đối với $E$. coli và $S$. Typhi lần lượt $40 \mu \mathrm{g} / \mathrm{mL}$ và $60 \mu \mathrm{g} / \mathrm{mL}$ là (Archana \& ctv., 2011). Kết quả nghiên cứu của Tiwari và ctv. (2005) cũng xác định được nồng độ ức chế tối thiểu của dịch chiết từ chè đối với $E$. coli là $88,3 \mathrm{mg} / \mathrm{mL}$; đối với $S$. Typhi và $S$. Typhimurium $1402 / 84$ lần lượt là $79,56 \mathrm{mg} / \mathrm{mL}$ và $94,61 \mathrm{mg} / \mathrm{mL}$.

Kết quả ở Bảng 1 còn cho thấy nồng độ ức chế tối thiểu cao chiết từ chè xanh đối với $S$. aureus ATCC 25923 là $0,5 \mathrm{mg} / \mathrm{mL}$. Kết quả này khá tương đồng với nghiên cứu của Maksum \& ctv. (2013), nhóm tác giả cũng khẳng định giá trị MIC của dịch chiết chè xanh đối với $S$. aureus là 0,4 mg/mL. Một nghiên cứu khác của Aboulmagd \& ctv. (2011) cũng ghi nhận được nồng độ ức chế tối thiểu đối với $S$. aureus ATCC 25923 là 0,78 $\mathrm{mg} / \mathrm{mL}$. 


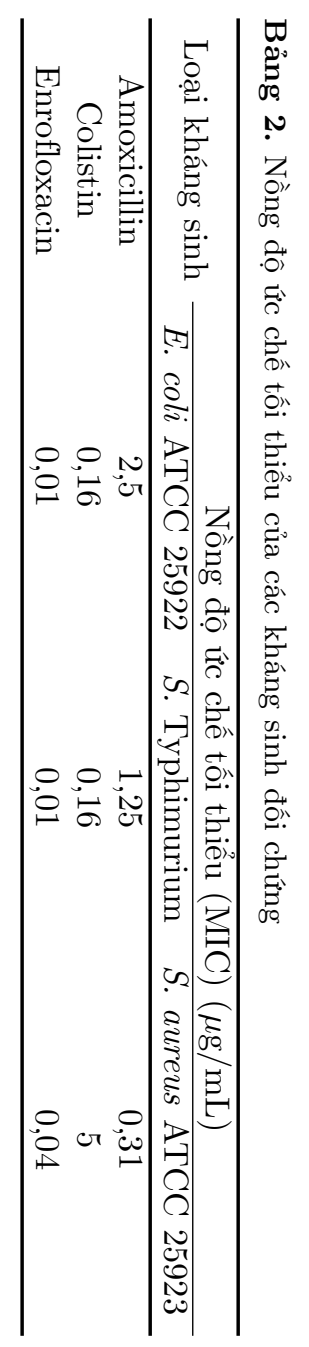

- Nồng độ ức chế tối thiểu của cao thô hoàn ngọc:

Từ Bảng 1 , cho thấy hoàn ngọc thể hiện hoạt tính kháng khuẩn đối với $S$. Typhimurium tương đối mạnh hơn so với E. coli. Nguyen \& Eun (2013) khẳng định dịch chiết của từ cây hoàn ngọc có khả năng ức chế sự phát triển của $E$. coli ở nồng độ $1,25 \mathrm{mg} / \mathrm{mL}$ thấp hơn 6,4 lần so với kết quả của nghiên cứu này. Nghiên cứu khác của Bongkot \& ctv. (2009) cho thấy dịch chiết nước của hoàn ngọc có nồng độ ức chế tối thiểu đối với Salmonella phân lập từ heo và người là $0,78 \%$. Kết quả ở Bảng 1 còn cho thấy, cao chiết thô từ lá hoàn ngọc có nồng độ ức chế tối thiểu đối với S. aureus ATCC 25923 dao động từ $2-4 \mathrm{mg} / \mathrm{mL}$ tương đương amoxicillin $(0,31 \mu \mathrm{g} / \mathrm{mL})$, colistin (5 $\mu \mathrm{g} / \mathrm{mL})$ và enrofloxacin $(0,04 \mu \mathrm{g} / \mathrm{mL})$.

- Nồng độ ức chế tối thiểu của cao thô cỏ mực và lá ổi:

Ngoài ra, từ kết quả Bảng 1 thấy rằng, $\mathrm{MIC}$ của cao thô cỏ mực đối với $S$. aureus ATCC 25923 dao động từ $1-2 \mathrm{mg} / \mathrm{mL}$; trong khi MIC của cao thô lá ổi đối với chủng vi khuẩn này là $0,125-0,25$ $\mathrm{mg} / \mathrm{mL}$, kết quả này thấp hơn so với công bố của Sanches \& ctv. (2005). Nghiên cứu của Pandey \& ctv. (2011) cũng xác định được giá trị MIC của cao chiết từ cỏ mực đối với $S$. aureus lớn hơn 0,7 $\mathrm{mg} / \mathrm{mL}$.

- Nồng độ ức chế tối thiểu của cao thô sầu đâu (neem):

Dịch chiết lá sầu đâu (neem) cho thấy nồng độ ức chế tối thiểu đối với cả ba chủng vi khuẩn thử nghiệm là lớn hơn $16 \mathrm{mg} / \mathrm{mL}$. Kết quả này cao hơn nồng độ ức chế tối thiểu của cao chiết bằng nước từ lá sầu đâu (neem) đối với $S$. aureus được công bố bởi Raja \& ctv. (2013) là $0,5 \mathrm{mg} / \mathrm{mL}$. Nghiên cứu của Maragathavalli \& ctv. (2012) không ghi nhận được hoạt tính kháng khuẩn của dịch chiết từ lá sầu đâu (neem) đối với cả $E$. coli và $S$. Typhimurium.

\section{Kết Luận và Đề Nghị}

Nghiên cứu đã bước đầu xác định cao thô chiết từ lá chè, cỏ mực, hoàn ngọc và ổi có khả năng chống 3 vi khuẩn thử nghiệm với các giá trị MIC từ $0,125-16 \mathrm{mg} / \mathrm{mL}$. Đặc biệt, giá trị MIC của các cao thảo dược thấp nhất đối với $S$. aureus ATCC 25923. Các loại dược liệu này rất phổ biến, dễ tìm ở Việt Nam, do vậy tiềm năng ứng dụng các loại dược liệu này trong phòng và trị bệnh cho vật nuôi là rất lớn. Tuy nhiên cần nghiên cứu 
thêm hoạt tính kháng khuẩn của các loại dược liệu này trên các nhóm vi khuẩn khác nhằm làm tăng thêm cơ sở dữ liệu phục vụ cho nghiên cứu và ứng dụng. Ngoài ra, các nghiên cứu về độc tính của các loại dược liệu này cũng rất cần thiết.

\section{Lời Cảm Ơn}

Nhóm nghiên cứu chân thành cảm ơn quỹ nghiên cứu Khoa học và Công nghệ, Trường Đại học Nông Lâm Thành phố Hồ Chí Minh đã tài trợ cho nghiên cứu này.

\section{Tài Liệu Tham Khảo (References)}

Aboulmagd, E., Al-Mohammed, H. I., \& Al-Badry, S. (2011). Synergism and post antibiotic effect of green tea extract and imipenem against methicillin resistant Staphylococcus aureus. Journal of Microbiology 1(3), 89-96.

Amber F., Adnan, K., Ilaria, B., Shahana, U. K., Salvatore, R., \& Bianca, P. (2015). Synergistic Antimicrobial Activity of Camellia sinensis and Juglans regia against Multidrug-Resistant Bacteria. Plos One 10(2), 1371.

Archana S., \& Abraham J. (2011). Comparative analysis of antimicrobial activity of leaf extracts from fresh green tea and black tea on pathogens. Journal of Applied Pharmaceutical Science 1(8), 149-152.

Bongkot, N., Sunpetch, A., Natchaya, P., \& Wisarut, M. (2009). Inhibitory and bactericidal effects of Pseuderanthemum palatiferum and Piper betle L. leaves extracts against Salmonella species. KKU. Veterinary Journal 19(2), 171-179.

Do, B. H. (2006). Medicinal plants and animals in Vietnam 1, 404-419. Ha Noi: Science and Technics Publishing House.

Gustafson, R. H., \& Bowen, R. E. (1997). Antibioticuse in animal agriculture. Journal of Applied Microbiology $83,531-541$.

Madhab, K. C. (2014). Use of antibioticts as feed additives: a burning question. Frontier Microbiology 5, 334.

Maksum, R., Rafael, A. A., Berna, E., \& Conny, R. S. (2013). Antimicrobial activity of green tea extract against isolates of methicillinresistant Staphylococcus aureus and multidrug resistant Pseudomonas aeruginosa. Asian Pacific Journal of Tropical Biomedicine 3(8), 663-667.

Maragathavalli, S., Brindha, S., Kaviyarasi, N. S. B., Annadurai, B., \& Gangwar, S. K. (2012). Antimicrobial avtivity in leaf extract of neem (Azadirachta indica Linn.). International Journal of Science and Nature 3(1), 110-113.
Nguyen, L. T. K. (2012). Effects of garlic and turmeric on disease resistance and growth performance of 30 to 90day-old pigs and finisher pigs (Unpublished doctoral dissertation). Nong Lam University, Ho Chi Minh City, Vietnam.

Nguyen, V. Q., \& Eun, J. B. (2013). Antimicrobial activity of some Vietnamese medicinal plants extracts. Journal of Medicinal Plants Research 7(35), 25972605.

Pandey, M. K., Singh, G.N., Sharma, R. K., \& Lata, S. (2011). Antibacterial activity of Eclipta alba (L.) Hassk. Journal of Applied Pharmaceutical Science 1(7), 104-107.

Raja, R. R. Y, Krishna, K. C, Lokanatha, O, Mamatha, S., \& Damodar, R. C. (2013). Antimicrobial activity of Azadirachta Indica (neem) leaf, bark and seed extracts. International Journal of Research in Pharmacology and Phytochemistry 3(1), 1-4.

Sanches, N. R., Garcia Cortez, D., Schiavini, M. S., Nakamura, C. V., \& Dias Filho, B. P. (2005). An Evaluation of Antibacterial Activities of Psidium guajava (L.). Brazilian Archives of Biology and Technology 48(3), 429-436.

Tiwari, R. P., Bharti, S. K., Kaur H. D., Dikshit R. P., \& Hoondal G. S. (2005). Synergistic antimicrobial activity of tea \& antibioticts. Indian Journal of Medical Research 122(1), 80-84.

Victor, L. (2005). Antibiotics in Laboratory Medicine. Philadelphia, USA: Lippincott Williams \& Wilkins.

Vo, A. T. T., Marshall, B. M., Levy, S., Ochieng, D., Gur, D., Nanuashvili, A., Kim, Y. S., Byarugabe, D. K., Okoh, A., Kashyap, S. K., Endtz, H., \& Sosa, A. (2010). Surveillance of antibiotic resistance determinants in commensal and environmental bacteria from international sources. Interscience Conference on Antimicrobial Agents and Chemotherapy. Boston, Massachusetts, USA.

Vo, A. T. T., van Duijkeren E., Fluit A. C., Heck M. E., Verbruggen A., Maas H. M., \& Gaastra W. (2006). Distribution of Salmonella enterica serovars from humans, livestock and meat in Vietnam and the dominance of Salmonella Typhimurium phage type 90. Veterinary Microbiology 113(1-2), 153-158.

Wiegand, I., Hilpert, K., \& Hancock, R.E.W. (2008). Agar and broth dilution methods to determine the minimal inhibitory concentration (MIC) of antimicrobial substances. Nature Protocols 3(2), 163-175. 